\title{
The Effects of Access and Accessibility on Public Transport Users' Attitudes
}

\author{
Subeh Chowdhury, Kasey Zhai, and Asif Khan \\ University of Auckland, New Zealand
}

\begin{abstract}
This study investigates existing users' attitudes towards public transport from two perspectives. First, the effects of accessibility to various destinations and ease of access to terminals on public transport users' attitudes are determined. Second, the contribution of social norm, as an information source, in the formation of users' attitudes is assessed. A user-preference survey was undertaken in Auckland, New Zealand, at two terminals. Data were analyzed using ordinal and logistic regression models. Findings showed that residential density and quality of the built environment, particularly safety, have an effect on the number of pedestrians who access a terminal. Accessibility to various destinations, "reaching work/education," and "reaching other suburbs" in both data sets were statistically significant for existing users' satisfaction with the current system. The findings also show that negative experiences of others have an adverse effect on existing users' intentions to continue ridership. Overall, the results showed that to retain existing patronage, the ease of access to terminals and connectivity to various destinations need to be of a high standard.
\end{abstract}

Keywords: Public transport, attitude, access, walking

\section{Introduction and Research Objectives}

Achieving user-friendly public transport (PT) systems has become an increasingly crucial goal for urban transport planning due to road transport contributing significantly towards climate change (Uherek et al. 2010). Emissions of $\mathrm{CO}_{2}$ from the road transport sector are in an upward trend (Black and Sato 2007); private vehicles have been identified as a main contributor to greenhouse gas (GHG) emissions (Chapman 2007). In addition to air pollution, other issues such as noise pollution and traffic congestion also have been linked with travelers' heavy reliance on private vehicles. Delays caused by congestion have been estimated to cost businesses billions every year (Brog et al. 2009). A key climate change mitigation strategy recommended by the Intergovernmental Panel on Climate Change (IPCC) is to create modal shift from private vehicles to PT (Stanton et al. 2013). As such, globally, government agencies are adapting their regional transportation 
planning process to prioritize and encourage the development and use of PT (Handy 2008). With trip making behavior growing in complexity in terms of purpose and spatial destinations, operators and planners continue to face the challenge of providing travelers with an attractive system (Hensher and Reyes 2000; Chowdhury et al. 2015).

Access to and the accessibility of PT systems has always been focal service issues. The other issue that effects PT use is the attractiveness of private vehicles. Private vehicle use has been preferred to PT not only for its instrumental functions (freedom, comfort, and convenience) but also for its symbolic (status in society) and affective (driving is perceived as being pleasurable) functions (Hiscock et al. 2002; Beirao and Sarsfield-Cabral 2007). Therefore, the loyalty of existing PT users to continue ridership is uncertain. Mavoa et al. (2012) states that there is a relatively small number of research on accessibility using PT. To the authors' knowledge, there exists a gap in the literature on how accessibility of a PT network influences existing users' attitudes and thereby retains loyalty. Literature analyzing the general attitude of travelers towards PT use has shown that although improvement in service quality is likely to increase ridership, the level of increase can be limited if travelers hold prejudices towards the image of PT (Murray et al. 2010). Such studies have identified the importance of attitude in travelers' willingness to use PT. Attitude is defined as an individual's positive or negative evaluation of performing an intended action (Ajzen 2005). In addition to attitude, it has been found that travelers' intentions to select PT is influenced by social norm (Bamberg et al., 2007). Social norm is defined by Ajzen (2005) to be a reflection of an individual's perceptions of the social pressures that are in place to perform or not perform a certain action. Karash et al. (2008) discussed that social norm can act as an easily accessible and comprehendible information source for outcome formation. Klockner and Matthies (2004) discussed that internalized social norms can assist in the shaping of attitude towards a particular action.

The present study investigates existing users' attitudes towards PT from two perspectives. First, the effects of accessibility to destinations and ease of access to terminals on existing users' attitudes is determined. A terminal is defined as a hub, station, or transfer point. Second, the contribution of social norm, as an information source, in the formation of users' attitudes towards PT is assessed. Selected elements of the built environment surrounding terminals and network connectivity were used to measure access and accessibility, respectively. A user-preference survey was conducted in Auckland, New Zealand. A travel survey conducted by the Ministry of Transport (2014) between 2010 and 2013 indicated that in terms of modal share, PT has a 2.8\% share in New Zealand. The findings of this study are expected to assist planners and operators in attracting and retaining patronage. The next section provides a review of literature and is followed by discussion of the hypothesis. A description of the survey implementation, results and discussion, and conclusions complete the paper.

\section{Literature Review}

This section provides a literature review that discusses the importance of accessibity to various destinations through network coverage and ease of access to terminals in encouraging travelers to use PT. 


\section{Accessibility}

One of the key measures of accessibility is providing access to different activities/ opportunities (Mavoa et al. 2012). The other measure is time-based (walking time to stop and journey time). Accessibility can be determined by the network coverage of a PT system and access by active modes (walking and cycling) to different land uses. Bertolini et al. (2005) stated that integration of land use planning and transport is a critical component in achieving sustainable development. The study emphasized the shift of focus from planning for mobility to planning for accessibility to access sustainable travel options more effectively. Manaugh and El-Geneidy (2012) discussed that high accessibility at a regional level leads to more sustainable travel outcomes such as shorter travel distances, which produced shorter journey times. Land use mixture also has been shown to influence travel behavior. Manaugh and Kreider (2013) discussed that it is not the proportion of various land uses that is important; rather, it is the level of interaction among land uses. Fine-grained mixing of complementary land uses creates opportunities for walking, cycling, and use of PT to reach desired destinations. Residents of mixed-use urban areas were seen to make shorter journeys. Zhang et al. (2012) also suggested that compact, mixed-use developments are effective in reducing vehicles miles traveled (VMT) per person through shorter journeys.

\section{Access to Public-Transport Terminals}

A critical factor in PT use is the access time or distance of a terminal/stop (Murray 2001). Saelens and Handy (2008) discussed that the ease of access is influenced by factors such as the aesthetic quality and attractiveness of the environment, infrastructure provision, and street connectivity. Walkable environments most often are defined by the presence of appropriate physical elements of the built environment. This includes high-quality visual amenity and architectural design, pedestrian supporting infrastructure, and street connectivity and permeability (Bently et al. 1985; Speck 2012). Speck (2012) explains that environments must first provide the appropriate conditions to encourage walking and PT use. In addition to an efficient PT network, such environments need to ensure personal safety and be comfortable, interesting, and stimulating. Saelens and Handy (2008) found that greater street connectivity can provide a higher variety of route choices that ensure that journeys remain interesting. Neighborhoods with a permeable and integrated road network can offer more direct route choices for both pedestrians and services, thereby increasing the appeal of PT. The aesthetic quality and attractiveness of an environment often are determined by the façade of buildings. Varied visual architecture and public frontages that line streets with activities are more likely to create neighborhoods that feel secure, comfortable, and interesting. Borjesson (2012) states that a key factor for perceived and actual personal safety when accessing terminals/stops is the design of the built environment. Features such as footpaths with clear sight distance and public spaces contribute to pedestrians feeling secure.

\section{Definition of Attitude and Social Norm}

Studies by Carrus et al. (2008) and Eriksson and Forward (2011) confirmed that both attitude and social norm can accurately predict travel behavior. Banaji and Heiphetz (2010) stated that attitude is "a psychological tendency that is expressed by evaluating a particular entity with some degree of favour or disfavour." Attitude is determined by the 
beliefs about the consequences of a behavior (Ajzen 1991). It is underlined by behavioral beliefs, which are determined by an individual's evaluation of all possible outcomes associated with conducting an action. The outcomes are identified using existing and accessible information. Whether an individual has a positive or negative attitude towards PT will depend on whether positive or negative evaluations are associated with its use. Furthermore, according to Klockner and Matthies (2004), attitude is shaped partly by personal norms, which are described to be internalized social norms. Social norm is defined as the individual's perception of social obligation and important referents' expectation to perform or not perform the intended action (Kallgren et al. 2000). This norm is underlined by normative beliefs that are an individual's belief of referents' expectation for performance or non-performance of the behavior. Normative beliefs also are determined by an individual's motivation to comply and the fear of social sanctions (Bamberg et al. 2007). An individual is more likely to perform an action when normative beliefs indicate that there is social pressure and expectation to do so or when there is a stigma attached to alternative actions or inaction.

\section{Assumptions}

Terminals that are both surrounded by and appropriately connected to residential dwellings and commercial uses provide greater accessibility as well as a range of destination choices for travelers entering and egressing. The design of the built environment can lead to the characterization of neighborhoods as being "walkable" or "PT-oriented" (Stewart and Moudon 2014). Connective street layouts can reduce journey time and increase destination choice and PT accessibility (Bently et al. 1985). The appearance and design features of the public streetscape such as building façades and pedestrian infrastructure contribute to create safe, interesting, and comfortable walking environments for travelers when accessing PT (Borjesson 2012; Speck 2012). According to this point of view, the first assumption (A1) is proposed. Murray (2003) states that it is relatively straightforward to determine service access provided spatial information exists to examine the proximity from locations of interest to PT terminals. As the present study is in regards to perceived accessibility, the existing users' attitudes towards PT use was measured by determining the ease of accessibility to various destinations through network coverage and ease of access to terminals.

A1: Accessibility to different land uses by the public transport system and ease of access to terminals has an effect on existing users' attitudes towards public transport.

Studies (Bamberg et al. 2007; Karash et al. 2008) confirm that social norms have a lesser influence on intention than attitude. Bamberg et al. (2007) explains that social norms influence behavior through an individual's fear of social sanctions. Although social norms are found to have a weak influence on intention, they can act as an easilyaccessible and comprehendible information source for outcome evaluation. Accordingly, the second assumption (A2) is whether the views of others towards PT serve as an information source for the formation of users' attitudes. This was measured by assessing the relevance of the views, actions, or previous experiences of important referents on users' attitudes and, thereby, their intention to continue ridership. 
A2: Social norms are used as an information source in the formation of existing public transport users' attitudes.

\section{Survey Design}

\section{Survey Locations}

The survey locations chosen for this study were Constellation Station (L1) and Papakura Transport Centre (L2) in Auckland, New Zealand. The locations were selected due to differences between the network coverage from the terminals and the ease of access to the terminals. L1 is located approximately 15 kilometers north of Auckland's central business district (CBD) and is one of the five stations in Auckland's bus rapid transit, the Northern Busway. Local feeder routes are connected to the station, thus allowing greater destination choices. As such, PT users are able to use a number of bus services that are directly connected to the city center and neighboring suburbs. A study by Ceder et al. (2009) on the connectivity of the Northern Busway showed that the routes of the busway have greater connectivity compared to alternative routes within Auckland. L2 is located approximately 35 kilometers south of Auckland's CBD, from which users have access to both bus and train services that focus on providing a link between the Papakura suburb and the $\mathrm{CBD}$. The bus service has no priority provisions. Both locations provide parkand-ride facilities free of charge, with 370 spaces in L1 and 230 in L2 (Auckland Transport 2015). Site visits indicated that parking spaces are fully utilized within the morning peak period. Figure 1 shows the geographical location of the two terminals.

FIGURE 1.

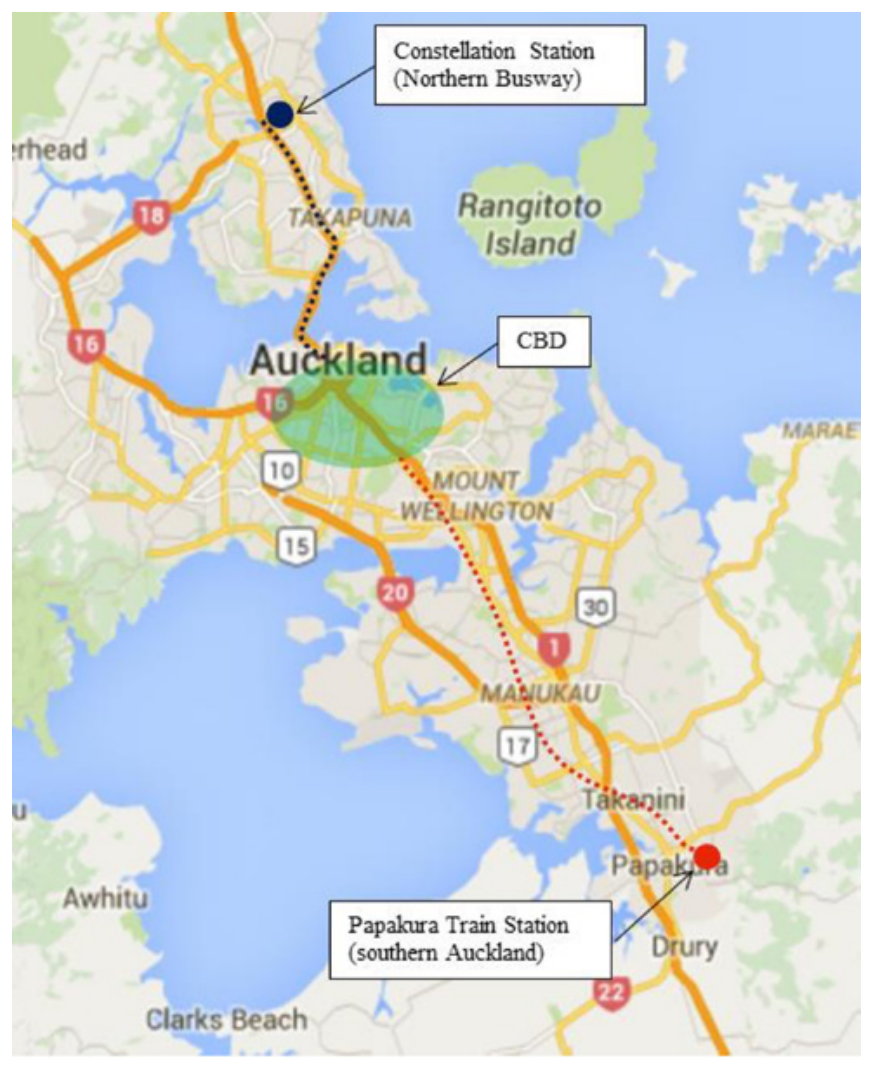

Adapted from Google Maps 
Within a five-kilometer radius, $\mathrm{L} 1$ is adjacent to and surrounded by a diverse range of commercial facilities, including a major shopping mall. Such facilities are directly accessible through existing PT services that closely link the terminal to neighboring stations. L2 is an isolated terminal located south of Auckland city. Within a fivekilometer radius, $\mathrm{L} 2$ is surrounded by suburban neighborhoods that drastically transition into rural property lots of a lower residential density (Auckland Council 1999). The closest major shopping mall is located approximately 13 kilometers north and is accessible by PT services. Figure 2 illustrates the different surrounding residential density and land uses of the two locations, and Figure 3 demonstrates the locality of the two terminals. Due to the differences in the surrounding residential densities of L1 and L2, L1 can be accessed by a greater number of residents.

FIGURE 2.

L1 and L2 surrounding land use
Constellation Station (L1)

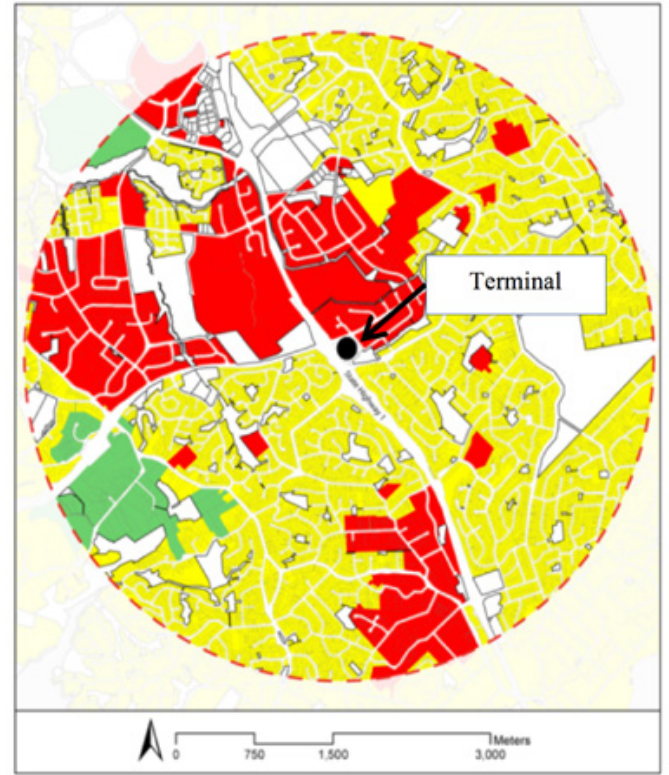

Legend

Suburban Residential

Rural Residential
Business and Community Open Space and Vacant Land
Papakura Interchange (L2)

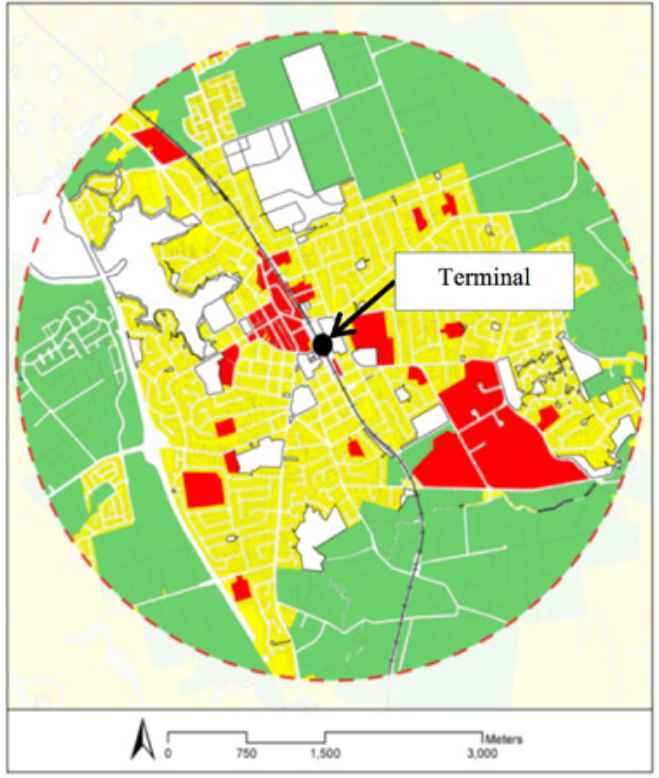

- Survey Location $5 \mathrm{~km}$ Radius from Station

Source: Auckland Council District Plan (1999) 
FIGURE 3.

Locations of L1 and L2

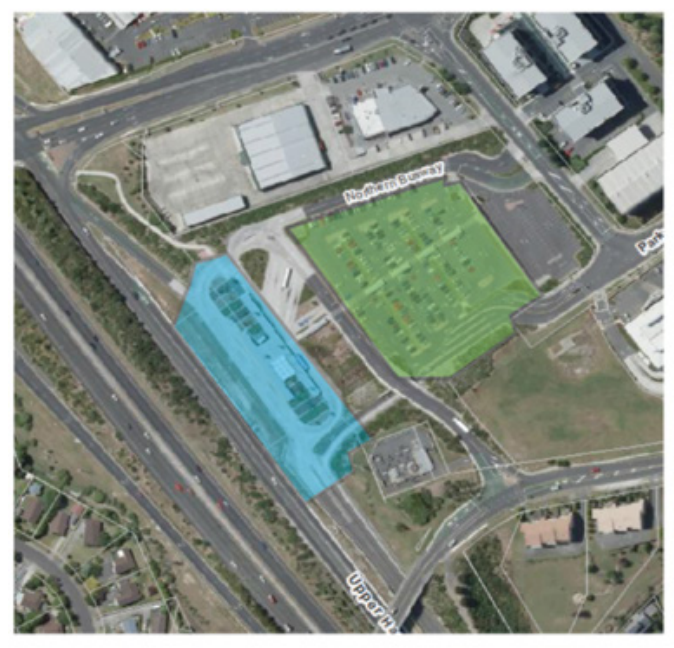

Constellation Station (L1)

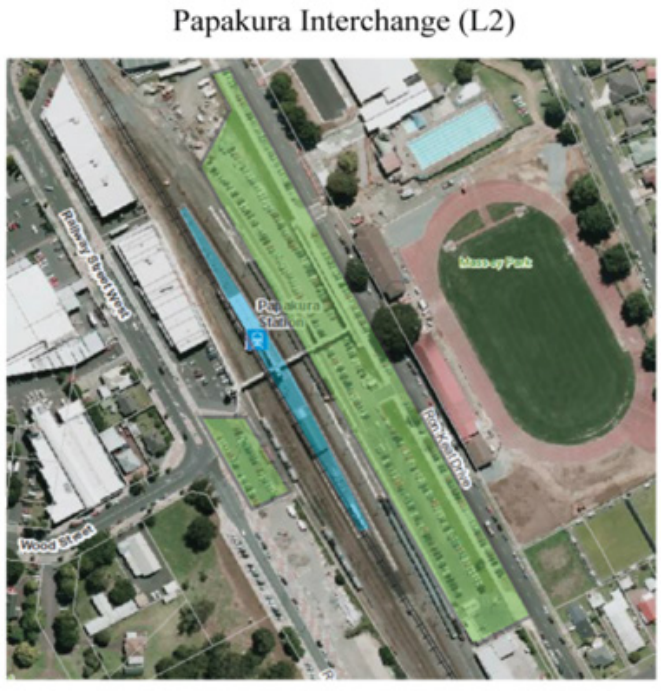

Legend

Waiting/Boarding Area

Parking Area

Adapted from Google Maps

Note: A neutral point ("no opinion") was included in the scale to acquire responses for all items in the questionnaire and to retain the interest of participants (Crano and Brewer 2002; Singleton and Straits 2005).

In terms of the street network design, $\mathrm{L} 1$ is located adjacent to a major highway and is surrounded by a network of cul-de-sacs that form irregularly-shaped urban blocks. These factors decrease permeability and compromise access to the terminal from the southwestern side, particularly for pedestrians. L2 is surrounded by a grid-like network in which urban blocks range between 90 and 400 meters, leading to varying degrees of permeability and comparatively easier access by walking within the immediate proximity of the terminal. Site visits indicated that $\mathrm{L} 1$ and its surroundings have better lighting than $\mathrm{L} 2$ for night journeys. Both terminals are surrounded by commercial and residential uses, which create active street frontages that increase feelings of suirvellance and personal safety.

\section{Questionnaire}

The questionnaire was designed to be completed within five minutes while PT users were waiting for their vehicle to arrive. For this reason, socio-demographic and trip characteristics question were limited to gender, age, and frequency of PT use. Table 1 provides the measurement items included in the questionnaire, categorized according to the themes. An option "Please tick if not applicable" was provided to participants. A 5-point Likert Scale (strongly agree to strongly disagree) was used as the response scale and was designed to measure one specific perception of the item presented to the respondent (May 2011). The Likert Scale represents one of the most adopted approaches for generating reliable scales of individual differences (Crano and Brewer 2002; Singleton and Straits 2005) and has been commonly used in travel behavior studies (Heath and Gifford 2002; Bamberg et al. 2007; Gatersleben and Uzzell 2007; Carrus et al. 2008). 
TABLE 1.

Measurement Items in Questionnaire

\begin{tabular}{|c|c|c|}
\hline Category & Description & $\begin{array}{l}\text { Code or } \\
\text { Unit* }\end{array}$ \\
\hline \multirow{2}{*}{$\begin{array}{l}\text { Attitude and } \\
\text { Intention }\end{array}$} & I am satisfied with the PT system. & 1 \\
\hline & Do you intend to continue using PT within the next 6 months? & 2 \\
\hline \multirow{5}{*}{$\begin{array}{l}\text { Access to } \\
\text { Terminals } \\
\text { (L1 and L2) }\end{array}$} & The ideal time taken to access PT by walking. & 3 \\
\hline & The ideal time taken to access PT by driving. & 3 \\
\hline & When walking between home and station, I feel safe at all times of the day. & 1 \\
\hline & When walking between home and station, I feel safe from vehicular traffic. & 1 \\
\hline & $\begin{array}{l}\text { When walking between home and station, I feel there are comfortable } \\
\text { footpaths. }\end{array}$ & 1 \\
\hline \multirow{4}{*}{$\begin{array}{l}\text { Accessibility of } \\
\text { Destinations } \\
\text { (Network } \\
\text { Coverage) }\end{array}$} & I can use PT to reach recreational activities with ease. & 1 \\
\hline & I can use PT to reach work and/or education with ease. & 1 \\
\hline & $\begin{array}{l}\text { I can use PT to run errands with ease (supermarket, post office, medical } \\
\text { clinic, etc.). }\end{array}$ & 1 \\
\hline & I can use PT to reach other suburbs within Auckland with ease. & 1 \\
\hline \multirow{3}{*}{$\begin{array}{l}\text { Social Norms } \\
\text { as Information } \\
\text { Source }\end{array}$} & I take PT because someone whose opinion I value believes that I should. & 1 \\
\hline & $\begin{array}{l}\text { My choice to take PT is influenced by someone close to me doing the same } \\
\text { (family/friend/colleague). }\end{array}$ & 1 \\
\hline & $\begin{array}{l}\text { I will not use PT in a given situation if someone I know had a bad } \\
\text { experience with the same service. }\end{array}$ & 1 \\
\hline
\end{tabular}

*Code/Unit 1: 1 = Strongly Agree, $2=$ Agree, $3=$ Neutral, $4=$ Disagree, $5=$ Strongly Disagree

** Code/Unit 2: Yes/No

${ }^{* * *}$ Code/Unit 3: $1=0-5$ minutes, $2=6-10$ minutes, $3=11-15$ minutes

\section{Limitations of Survey}

This study required a sample of existing PT users. It was not possible to obtain a sampling frame of PT users; however, an effort was made to select the partcipants randomly. Sample selection bias was mitigated by selecting every third PT user entering the stations. It is to be noted that the sample represents a random sample of only existing PT users who were undertaking their morning commute at the two survey locations. A pilot survey included both the morning (7:00-9:00 AM) and evening (4:006:00 PM) peak periods. In the pilot survey, the response rate in the evening peak was less than $10 \%$ and in the morning peak it was around $80 \%$ at both $L 1$ and L2. This is due to the limited number of users willing to participate in the evening peak period. After being briefly informed of the research purpose, commuters were invited to participate and complete the self-administered questionnaire.

\section{Results and Discussion}

\section{Data Summary}

A total of 356 questionnaires were distributed among the two survey locations, of which 300 were completed and deemed suitable for analysis. Both locations received a high response rate of approximately $90 \%$. Questionnaires deemed unsuitable for analysis were due to incompletion, of which 48 of the 56 originated in L1 and 8 in L2. This was due to higher service frequencies and shorter waiting times at L1, providing participants with less time for completion. 
The completed questionnaires comprised 160 from L1 and 140 from L2. The most common trip destination for commuters from both locations was the CBD, contributing to $48 \%$ of trips from L1and $43 \%$ of trips from L2. Within L2, $92 \%$ of the trips originated from the Papakura suburb, and the remaining $8 \%$ were from neighboring adjacent suburbs. The station does not serve as a frequent transfer point, as all journeys originated from the station. At $\mathrm{L} 1,84 \%$ of the trips originated from the station, with residents from the Constellation suburb and neighboring adjacent suburbs. The remaining $16 \%$ were from other suburbs within Auckland City, for which the station was used as a transfer point. A summary of the participants' sociodemographic characteristics and trip frequency at each location is shown in Table 2. Figure 4 illustrates that the most common response category to the measurement item "I am satisfied with the public transport system" was "Agree" (41\%) in L1 and "Neutral" (32\%) in L2. Overall, participants showed greater satisfaction in L1; $57 \%$ of participants selected "Agree" and "Strongly Agree" compared to 38\% of the participants in L2.

TABLE 2.

\begin{tabular}{|l|c|c|c|}
\hline \multicolumn{2}{|c|}{} & L1 Data Set & L2 Data Set \\
\hline \multirow{2}{*}{ Gender } & Male & $49 \%$ & $42 \%$ \\
\cline { 2 - 4 } & Female & $48 \%$ & $56 \%$ \\
\hline \multirow{3}{*}{ Age } & $18-30$ & $62 \%$ & $43 \%$ \\
\cline { 2 - 4 } & $31-50$ & $30 \%$ & $41 \%$ \\
\cline { 2 - 4 } & $51-65$ & $6 \%$ & $14 \%$ \\
\cline { 2 - 4 } & $65+$ & $2 \%$ & $1 \%$ \\
\hline \multicolumn{2}{|c|}{ Frequent PT users } & $84 \%$ & $87 \%$ \\
\hline \multicolumn{2}{|c|}{$\mathrm{N}$ (sample size) } & 160 & 140 \\
\hline
\end{tabular}

FIGURE 4.

Commuter satisfaction with services at survey locations

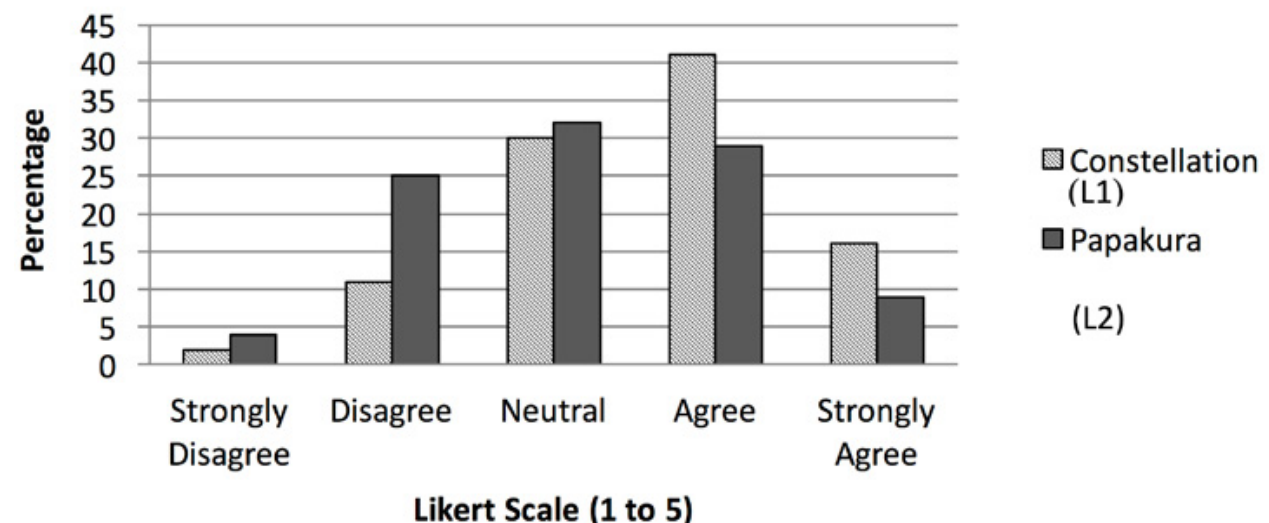

\section{Regression Analysis}

\section{Regression Model for A1}

Ordinal regression was performed using the data set from each location to assess the first assumption. This approach was used as it is suitable for the small sample size. The dependent variable, attitude, was measured through participants' satisfaction with the existing PT system. The response scale of the variables were a five-point Likert Scale $(1=$ 
Strongly Agree, $5=$ Strongly Disagree). The statistically significant independent variables $(p \leq 0.05)$ for each location are shown in Tables 3 and 4 . The measures of model fit (chisquare, goodness of fit, parallelism, and $\mathrm{R}^{2}$ ) indicate that the proposed models are a suitable fit for the L1 and the L2 data set (Kleinbaum and Klein 2010). In both data sets, the socio-demographic characteristics were not statistically significant in the models. A chi-squared test showed that the association of age to the locations is statistically significant. As indicated in Table 2, 62\% of the participants in L1 are within the age bracket of $18-30$ compared to $43 \%$ in L2.

TABLE 3.

Statistically Significant $\mathrm{H} 1$ Predictor Variables for L1

\begin{tabular}{|c|c|c|c|c|c|}
\hline $\begin{array}{l}\text { A1 Predictor Variables for } \\
\text { Constellation Data Set }\end{array}$ & $\begin{array}{l}\text { Reference } \\
\text { Category }\end{array}$ & $\begin{array}{l}\text { Response } \\
\text { Category }\end{array}$ & Estimate & $\begin{array}{l}\text { Odds } \\
\text { Ratio }\end{array}$ & P-value \\
\hline $\begin{array}{l}\text { Ideal time taken to access PT through } \\
\text { walking. }\end{array}$ & $\begin{array}{l}10-15 \\
\text { minutes }\end{array}$ & $\begin{array}{l}0-5 \\
\text { minutes }\end{array}$ & -1.322 & 0.27 & $0.018^{*}$ \\
\hline \multirow{3}{*}{$\begin{array}{l}\text { I can use public transport to reach work/ } \\
\text { education with ease. }\end{array}$} & \multirow{3}{*}{$\begin{array}{l}\text { Strongly } \\
\text { disagree }\end{array}$} & $\begin{array}{l}\text { Strongly } \\
\text { agree }\end{array}$ & -4.309 & 0.013 & $0.000^{* * *}$ \\
\hline & & Agree & -3.947 & 0.019 & $0.000^{* * *}$ \\
\hline & & Neutral & -2.746 & 0.064 & $0.013^{*}$ \\
\hline $\begin{array}{l}\text { I can use public transport to reach other } \\
\text { suburbs within Auckland with ease. }\end{array}$ & $\begin{array}{l}\text { Strongly } \\
\text { disagree }\end{array}$ & $\begin{array}{l}\text { Strongly } \\
\text { agree }\end{array}$ & -1.579 & 0.21 & $0.027^{*}$ \\
\hline Model fit & \multicolumn{5}{|c|}{$\begin{array}{l}\text { Chi-square }=0.000<0.05 \\
\text { Goodness of fit }=0.904>0.05 \\
\text { Parallelism }=0.263>0.05 \\
\mathrm{R}^{2}=0.42\end{array}$} \\
\hline
\end{tabular}

Note: $p$-value $<0.05^{*}, p$-value $<0.01^{* *}, p$-value $<0.001^{* * *}$

TABLE 4.

Statistically Significant $\mathrm{H} 1$ Predictor Variables for L2

\begin{tabular}{|c|c|c|c|c|c|}
\hline $\begin{array}{l}\text { A1 Predictor Variables for } \\
\text { Papakura Data Set }\end{array}$ & $\begin{array}{l}\text { Reference } \\
\text { Category }\end{array}$ & $\begin{array}{l}\text { Response } \\
\text { Category }\end{array}$ & Estimate & $\begin{array}{l}\text { Odds } \\
\text { Ratio }\end{array}$ & P-value \\
\hline Ideal driving time to a bus stop or station. & $\begin{array}{c}10-15 \\
\text { minutes }\end{array}$ & $\begin{array}{l}0-5 \\
\text { minutes }\end{array}$ & -1.414 & 0.24 & $0.006^{* *}$ \\
\hline \multirow{2}{*}{$\begin{array}{l}\text { I can use public transport to reach work/ } \\
\text { education with ease. }\end{array}$} & \multirow{2}{*}{$\begin{array}{l}\text { Strongly } \\
\text { disgree }\end{array}$} & $\begin{array}{l}\text { Strongly } \\
\text { agree }\end{array}$ & -2.080 & 0.12 & $0.019^{*}$ \\
\hline & & Neutral & -1.916 & 0.15 & $0.043^{*}$ \\
\hline $\begin{array}{l}\text { I can use public transport to reach other } \\
\text { suburbs within Auckland with ease. }\end{array}$ & $\begin{array}{l}\text { Strongly } \\
\text { disagree }\end{array}$ & Neutral & -1.857 & 0.16 & $0.005^{* *}$ \\
\hline Model fit & \multicolumn{5}{|c|}{$\begin{array}{l}\text { Chi-square }=0.000<0.05 \\
\text { Goodness of fit }=0.999>0.05 \\
\text { Parallelism }=0.215>0.05 \\
\mathrm{R}^{2}=0.36\end{array}$} \\
\hline
\end{tabular}

Note: $p$-value $<0.05^{*}, p$-value $<0.01^{* *}, p$-value $<0.001^{* * *}$

Within the L1 dataset, the variables "ideal walking time" ( $p$-value $=0.018$ ), "reaching work/education" ( $p$-value $=0.000)$, and "reaching other suburbs" ( $p$-value $=0.027$ ) were the statistically significant predictors of users' satisfaction. In other words, a lower Likert Scale rating of "Strongly Agree" or "Agree" was more likely to be selected by a participant in agreement with the measurement item for "reaching work/education" and "reaching other suburbs." This is represented by the negative value of the estimates. 
One explanation for this result is that PT services within $\mathrm{L} 1$ are well-connected to the $\mathrm{CBD}$ and adjacent suburbs. It also was found that the time desired by users to access a terminal is less than five minutes by walking ( $p$-value $=0.018$, estimate $=-1.322$ ). The predictor variables "ideal driving time" ( $p$-value $=0.006)$, "reaching work/education" ( $p$-value $=0.019)$, and "reaching other suburbs" ( $p$-value $=0.005)$ were statistically significant for users' satisfaction within the L2 dataset. Users were more likely to be satisfied when terminals can be accessed within five minutes by driving. Similar to L1, results of the regression model show that a low Likert Scale rating for satisfaction was associated with agreement to "reach work/education" and "reaching other suburbs" measurement items.

A1 results indicate the importance of addressing the issues related to the ease of access to terminals and accessibility to various destinations using PT as a travel mode in existing users' attitude. Results at both locations show that perceived ease of access to terminals has a statistically significant influence upon existing users' satisfaction with PT. Within the L1 dataset, walking time to access the terminal was statistically significant, whereas within the L2 dataset, driving time was statistically significant. Furthermore, it was found within the L1 dataset that $62 \%$ of participants walked to access PT compared to $34 \%$ within the L2 dataset. Such results may be explained by L1's surrounding built environment being more pedestrian-oriented than L2 in relation to safety and surveillance from a higher proportion of business and commercial land use. Another explanation is the high proportion of participants being under 30; young commuters are more likely to walk.

In terms of accessibility to various destinations using PT, in both data sets, "reaching work/education" and "reaching other suburbs" were statistically significant for existing users' satisfaction with the current PT system, and the ability to undertake errands or reach recreational activities were found to be statistically insignificant. This is a sensible result, as it reflects the activities that are suitable for PT. Trips for errands involve additional possessions such as luggage (e.g., shopping bags), which makes it physically difficult to use PT. Similarly, recreational trips are likely to involve strollers or bikes, which create constraints in using PT. Furthermore, it was found within both data sets that items measuring the presence of safe, comfortable, and interesting walking environments were not statistically significant predictors of attitude. An explanation for this result is that both L1 and L2 provide good quality built environments. As such, these items were not deciding factors in their choice to use PT.

Overall, results from regression models have shown that existing users from L1 exhibit positive attitudes towards PT. This may be attributed to the greater accessibility provided by the Northern Busway. For instance, work and education centred within the CBD can be reached by commuters from $\mathrm{L} 1$ within a shorter journey time than L2. This is due to both the geographic location and the provision of supporting infrastructure. The Northern Busway has a dedicated bus lane, which allows services to bypass congestion during morning and evening peak periods, increasing the performance of the service for commuter with trips originating from L1. PT services from $L 1$ also connect to adjacent suburbs. The neutral response within L2 indicates a certain amount of dissatisfaction towards the PT service. Reaching work and education 
within the $\mathrm{CBD}$ and other northbound suburbs is most likely the most predominant use of services from the terminal. Service performance may be limited by the station's isolated geographic location and limited accessibility to adjacent suburbs.

Along with the geographic location, the results also reflect the difference in the socio-demographic characteristics of the users. The frequency of services in L2 is less than $\mathrm{L} 1$, and time is a more critical factor for working commuters than students. The lower satisfaction of $L 2$ can be associated with the higher percentage of commuters age $\geq 30$ and lower percentage for those ages $18-30$. L2 has a higher proportion of female participants (56\%); females in a household are more likely to undertake trips for errands and, as such, the reduced accessibility offered by $L 2$ is reflected in the results for satisfaction.

\section{Regression Model for A2}

$A$ logistic regression model was undertaken to validate $A 2$. The dependent variable, participants' intention to use PT, was measured on a dichotomous response scale. The three independent variables are given in Tables 5 and 6 along with the results for L1 and L2, respectively. The Hosmer-Lemeshow test is a goodness-of-fit statistic used to determine whether the developed model reasonably approximates the data (Kleinbaum and Klein 2010).

TABLE 5.

A2 Predictor Variables for L1

\begin{tabular}{|l|c|c|c|}
\hline \multicolumn{1}{|c|}{ H2 Predictor Variables for Constellation Station } & Estimate & Odds Ratio & P-value \\
\hline $\begin{array}{l}\text { I take public transport because someone whose opinion I value } \\
\text { believes that I should. }\end{array}$ & -0.105 & 0.900 & 0.738 \\
\hline $\begin{array}{l}\text { My choice to take public transport is influenced by someone } \\
\text { close to me doing the same (family member/friend/colleague). }\end{array}$ & 0.066 & 1.069 & 0.831 \\
\hline $\begin{array}{l}\text { I will not use public transport in a given situation if someone I } \\
\text { know had a bad experience with the same service. }\end{array}$ & 0.611 & 1.842 & 0.033 \\
\hline Model fit & \multicolumn{2}{|l|}{ Hosmer-Lemeshow test $=0.63>0.05$} \\
\hline
\end{tabular}

TABLE 6.

\begin{tabular}{|l|c|c|c|}
\hline \multicolumn{1}{|c|}{ H2 Predictor Variables for Constellation Station } & Estimate & Odds Ratio & P-value \\
\hline $\begin{array}{l}\text { I take public transport because someone whose opinion I value } \\
\text { believes that I should. }\end{array}$ & 0.412 & 1.510 & 0.239 \\
\hline $\begin{array}{l}\text { My choice to take public transport is influenced by someone } \\
\text { close to me doing the same (family member/friend/colleague). }\end{array}$ & -0.148 & 0.862 & 0.600 \\
\hline $\begin{array}{l}\text { I will not use public transport in a given situation if someone I } \\
\text { know had a bad experience with the same service. }\end{array}$ & -0.008 & 0.992 & 0.976 \\
\hline
\end{tabular}

Results of the analysis indicated that the model for $\mathrm{L} 1$ adequately fits the dataset. During data collection, a number of participants verbally commented that the choice to take PT was their own when completing items related to obligation and willingness to comply with societal expectations. The use of PT is therefore shown to be a choice that is not influenced by an individual's perceptions of social obligations or the desire to gain the approval and acceptance of important referents $(p>0.05)$. However, the results indicate that social norms can serve as an information source used when forming attitudes towards PT. The experiences of other users influence an individual's 
willingness to ride a particular service ( $p$-value $=0.033$ ). The insignificance of this measurement item within L2 may be attributed to the lack of alternative travel modes. When making commuter trips for the purpose of work and education, users within the L2 surroundings are presented with travel options of driving with limited route choices or using the PT services available at L2. Due to this lack of choice, users are more likely to continue using existing PT services at L2 despite negative experiences. For instance, knowledge of a negative PT experience may still be more desirable than driving within peak-hour congestion. Overall, the findings within both $L 1$ and $L 2$ demonstrate that the action of using PT in Auckland is more likely to be influenced by self-interest rather than pro-social motives.

Future research will further investigate the factors within the information received from others that are most influential to attitude. Factors may include weather, safety and security, time-related attributes, crowding, and information.

\section{Conclusion}

Globally, countries are struggling with travelers' high dependency on private vehicles. Due to the comfort and flexibility offered by private vehicles, the loyalty of existing PT users to continue ridership is uncertain. The present study investigated existing users' attitudes towards PT from two perspectives. First, the effects of accessibility to destinations with PT and the ease of access to terminals on existing users' attitudes is determined; second, the contribution of social norms, as an information source, in the formation of users' attitudes towards the use of PT. Selected elements of the built environment surrounding terminals and network connectivity were used to measure access and accessibility, respectively. Two assumptions were tested. A user-preference survey was undertaken in Auckland, New Zealand, at two terminals with different provisions for service coverage and access. Data were analyzed using ordinal and logistic regression models.

Findings suggested that ease of access to terminals and accessibility to various destinations have an effect on existing users' satisfaction with ridership. This result raises the profile that although commuters have already decided to use PT, access to terminals and accessibility to various destinations remain as influential factors. "Reaching work/ education" and "reaching other suburbs" were statistically significant, and trips which included errands and recreational activities were insignificant. The result is sensible, as errands and recreational trips create physical obstacles due to additional commodities (e.g., grocery shopping bags, bikes, strollers). Within the L1 dataset, more PT users accessed the terminal by walking; in the L2 dataset, more users accessed by driving. This can be attributed to the built environment and residential density surrounding each location. The greater residential density surrounding $\mathrm{L} 1$ in conjunction with the better quality built environment, in terms of safety, enables higher volumes of pedestrians to access the terminal. Despite L1 being located adjacent to a major highway and being surrounded by cul-de-sacs that decrease permeability, the results of the study indicate that these two attributes of urban planning can successfully encourage affected residents to favor pro-environmental transport modes. In regards to the effects of social norms on attitude, the results found that social norms are used as a source of 
information by existing users. Negative experiences of others were seen to have an effect on existing users' intention to continue ridership in L1, where commuters are given higher-quality transport choices than L2 in terms of journey time and convenience. In summary, it is recommended that planners place importance on increasing the ease of access to terminals and accessibility to various destinations such that existing patronage can be sustained in the long term.

\section{References}

Ajzen, I. 1991. "The Theory of Planned Behavior." Organizational Behavior and Human Decision Processes, 50(2): 179-211.

Ajzen, I. 2005. Attitudes, Personality and Behavior 2. New York: McGraw-Hill.

Auckland Council. 1999. Auckland Council District Plan Operative Papakura Section 1999. Retrieved March 9, 2015, from http://www.aucklandcouncil.govt.nz/EN/ planspoliciesprojects/plansstrategies/DistrictRegionalPlans/papakuradistrictplan/ Pages/districtplanmapshome.aspx.

Auckland Transport. 2015. Park \& Ride. Retrieved December 15, 2015, from https:// at.govt.nz/driving-parking/parking-in-auckland/park-ride/.

Bamberg, S., M. Hunecke, and A. Blobaum. 2007. "Social Context, Personal Norms and the Use of Public Transportation: Two Field Studies." Journal of Environmental Psychology, 27(3): 190-203.

Banaji, M. R., and L. Heiphetz. 2010. Handbook of Social Psychology. New Jersey: John Wiley \& Sons, Inc.

Beirao, G., and J. A. Sarsfield-Cabral. 2007. "Understanding Attitudes Towards Public Transport and Private Car: A Qualitative Study." Transport Policy, 14(6): 478-489.

Bently, I., A. Alcock, P. Murrain, S. McGlynn, and G. Smith. 1985. Responsive Environment: A Manual for Designers. London: Architectural Press.

Bertolini, L., F. Le Clercq, and L. Kapoen. 2005. "Sustainable Accessibility: A Conceptual Framework to Integrate Transport and Land Use Plan-Making. Two TestApplications in the Netherlands and a Reflection on the Way Forward." Transport Policy, 12: 207-220.

Black, W. R., and N. Sato. 2007. "From Global Warming to Sustainable Transport 19892006." International Journal of Sustainable Transportation, 1(2): 73-89.

Borjesson, M. 2012. "Valuing Perceived Insecurity Associated with Use of and Access to Public Transport." Transport Policy, 22: 1-10.

Brog, W., E. Erl, I. Ker, J. Ryle, and R. Wall. 2009. "Evaluation of Voluntary Travel Behavior Change: Experiences from Three Continents." Transport Policy,16(6): 281-292.

Carrus, G., P. Passafaro, and M. Bonnes. 2008. "Emotions, Habits and Rational Choices in Ecological Behaviors: The Case of Recycling and Use of Public Transportation." Journal of Environmental Psychology. 28(1): 51-62. 
Ceder, A., Y. Le Net, and C. Coriat. 2009. "Measuring Public Transport Connectivity Performance Applied in Auckland." Transport Research Record, 2111: 139-147.

Chapman, L. 2007. "Transport and Climate Change: A Review." Journal of Transport Geography, 15(5): 354-367.

Chowdhury, S., A. Ceder, and B. Schwalger. 2015. "The Effects of Travel Time and Cost Savings on Commuters' Perception of Public Transport Routes Involving Transfers Using Just Noticeable Difference." Journal of Transport Geography, 43: 151-159.

Crano, W. D., and M. B. Brewer. 2002. Principles and Methods of Social Research, $2^{\text {nd }}$ Edition. Mahwah, New Jersery: Lawrence Erlbaum Associates, Inc.

Eriksson, L., and S. E. Forward. 2011. "Is the Intention to Travel in a Pro-Environmental Manner and the Intention to Use the car Determined by Different Factors?" Transportation Research Part D, 16: 372-376.

Gatersleben, B., and D. Uzzell. 2007. "Affective Appraisals of the Daily Commute." Environment and Behavior, 39(3): 416-431.

Handy, S. 2008. "Regional Transportation Planning in the US: An Examination of Changes in Technical Aspects of the Planning Process in Response to Changing Goals." Transport Policy, 15(2): 17-24.

Heath, Y., and R. Gifford. 2002. "Extending the Theory of Planned Behavior: Predicting the Use of Public Transportation." Journal of Applied Social Psychology, 32(10): 21542189.

Hensher, D. A., and A. J. Reyes. 2000. "Trip Chaining as a Barrier to the Propensity to Use Public Transport." Transportation, 27(4): 341-361.

Hiscock, R., S. Macintyre, A. Kearns, and A. Ellaway. 2002. "Means of Transport and Ontological Security: Do Cars Provide Psycho-Social Benefits to Their Users?" Transportation Research Part D, 7(2): 119-135.

Kallgren, C. A., R. R. Reno, and R. B. Cialdini. 2000. "A Focus Theory of Normative Conduct: When Norms Do and Do Not Affect Behavior." Personality and Social Psychology Bulletin, 26(8): 1002-1012.

Karash, K. H., M. A. Coogan, T. Adler, C. Cluett, S. A. Shaheen, I. Aizen, and M. Simon. 2008. "Understanding How Individuals Make Travel and Location Decisions: Implications for Public Transport." TCRP Report 123, Washington DC, Transportation Research Board: 1-147.

Kleinbaum, D. G., and M. Klein. 2010. Logistic Regression: A Self-Learning Text." New York: Springer.

Klockner, C., and E. Matthies. 2004. "How Habits Interfere with Norm-Directed Behavior: A Normative Decision-Making Model for Travel Mode Choice." Journal of Environmental Psychology, 24(3): 319-327.

Manaugh, K., and A. M. El-Geneidy. 2012. "What Makes Travel 'Local': Defining and Understanding Local Travel Behavior." Journal of Transport and Land Use, 5(3): 15-27. 
Manaugh, K., and T. Kreider. 2013. "What is Mixed Use? Presenting an Interaction Method for Measuring Land Use Mix." Journal of Transport and Land Use, 6(1): 63-72.

Mavoa, S., K. Witten, T. McCreanor, and D. O'Sullivan. 2012. "GIS-based Destination Accessibility via Public Transit and Walking in Auckland, New Zealand." Journal of Transport Geography, 20: 15-22.

May, T. 2011. Social Research: Issues, Methods and Process. Maidenhead, England: McGraw-Hill Education.

Ministry of Transport. 2014. "Comparing Travel Modes: New Zealand Household Travel Survey 2010-2013." Wellington, New Zealand: 1-19.

Murray, A. T. 2001. "Strategic Analysis of Public Transport Coverage." Socio-Economic Planning Sciences, 35: 175-188.

Murray, A. T. 2003. "A Coverage Model for Improving Public Transit System Accessibility and Expanding Access." Annals of Operations Research, 123: 143-156.

Murray, S. J., D. Walton, and J. A. Thomas. 2010. "Attitudes Towards Public Transport in New Zealand." Transportation, 37(6): 915-929.

Saelens, B. E., and S. L. Handy. 2008. "Built Environment Correlates of Walking: A Review." Medicine and Science in Sports and Exercise, 40: 1-14.

Singleton, R. A., Jr., and B. C. Straits. 2005. Approaches to Social Research, $4^{\text {th }}$ Edition. New York: Oxford University Press, Inc.

Speck, J. 2012. Walkable City: How Downtown Can Save America One Step at a Time. New York: Farrar, Straus and Giroux.

Stanton, N. A., R. C. Mcllroy, C. Harvey, S. Blainey, A. Hickford, J. M. Preston, and B. Ryan. 2013. Following the Cognitive Work Analysis Train of Thought: Exploring the Constraints of Modal Shift to Rail Transport." Ergonomics, 56(3): 522-540.

Stewart, O. T., and A. V. Moudon. 2014. Using the Built Environment to Oversample Walk, Transit and Bicycle Travel." Transportation Research Part D, 32: 15-23.

Uherek, E., T. Halenka, J. Borken-Kleefeld, Y. Balkanski, T. Berntsen, C. Borrego, M. Gauss, P. Hoor, K. Juda-Rezler, J. Lelieveld, D. Melas, K. Rypdal, and S. Schmid. 2010. "Transport Impacts on Atmosphere and Climate: Land Transport." Atmospheric Environment, 44: 4772-4816.

Zhang, L., J. Hong, A. Nasri, and Q. Shen. 2012. “How Built Environment Affects Travel Behavior: A Comparative Analysis of the Connections between Land Use and Vehicle Miles Traveled in US Cities." Journal of Transport and Land Use, 5(3): 40-52. 


\section{About the Authors}

SUbeh CHOwdhury (s.chowdhury@auckland.ac.nz) is a Lecturer at the University of Auckland in the Department of Civil and Environmental Engineering. She worked with two international engineering consultancies in New Zealand prior to joining the university in 2014 and has publications in reputable journals such as Transport Policy, Journal of Public Transportation, and Journal of Transport Geography.

KASEY ZHAI (kzha041@aucklanduni.ac.nz) is a final-year student at the School of Architecture and Planning at the University of Auckland. She received a summer scholarship from the Faculty of Engineering to conduct this research study.

AsIF KHAN (asif.khan@auckland.ac.nz) is a Senior Lecturer at the School of Architecture and Planning at the University of Auckland. He has more than 15 years of experience as an academic, including 10 years at the University of Sydney and the University of Auckland. He holds Ph.D. and Master of Urban and Regional Planning (Honours) degrees from the University of Sydney and a Bachelor of Civil Engineering degree from Bangladesh University of Engineering and Technology, Dhaka. His current research interests are in the areas of travel behavior, travel plans, and housing policies. 